Published in final edited form as:

Immunol Lett. 2014 October ; 161(2): 231-235. doi:10.1016/j.imlet.2014.04.004.

\title{
Inflammatory Bowel Disease
}

\author{
Daniele Corridonia,b Kristen O. Arseneau ${ }^{a, b}$, and Fabio Cominellia,b \\ aDepartment of Medicine, Case Western Reserve University, Cleveland, OH, USA \\ ${ }^{\mathrm{b}}$ Digestive Health Research Center, Case Western Reserve University, Cleveland, OH, USA
}

\begin{abstract}
Inflammatory bowel diseases (IBD), including Crohn's disease (CD) and ulcerative colitis (UC), are chronic, relapsing inflammatory condition of the gastrointestinal tract. $\mathrm{CD}$ and UC have distinct pathologic and clinical characteristics and despite the extensive amount of research conducted over the past decades, their pathogenesis remains still poorly understood. So far, the accepted dogma is that IBD results from dysregulated mucosal immune response to environmental factors in genetical susceptible hosts. Various components are implicated in the pathogenesis of IBD, including genetic susceptibility, environmental and microbial factors, intestinal epithelial cells and components of innate and adaptive immune system. Given the complexity of IBD, several different animal models of IBD have been developed during the last years. Animal models are very important tools to study the involvement of various factors in the pathogenesis of IBD and, importantly, to test new therapeutic options. This review examines some of the key components that have been found to be closely associated to IBD and describe the distinct features of some of the most important IBD models.
\end{abstract}

\section{Keywords}

Inflammatory bowel disease; Crohn's disease; Ulcerative colitis; Cytokine; Animal models

\section{Inflammatory Bowel Disease}

The idiopathic inflammatory bowel diseases (IBD) include two major forms of chronic intestinal disorders: Crohn's disease (CD) and ulcerative colitis (UC). IBD is the second most common inflammatory disease, affects approximately 1.4 million Americans, and has a peak onset between 15 and 30 years of age [1]. CD mostly involves the ileum and colon, but it can affect, often discontinuously, any region of the gastrointestinal tract. Ulcerative colitis involves the rectum and may affect a part, or the entire colon in a continuous pattern.

(c) 2014 Elsevier B.V. All rights reserved.

Corresponding Author: Fabio Cominelli, M.D., Ph.D., Case Western Reserve University School of Medicine, Division of Gastroenterology, 11100 Euclid Avenue, Cleveland, Ohio 44106-5066 Phone: +1(216) 844-7344, Fax: +1(216) 844-7371, fabio.cominelli@uhhospitals.org.

Publisher's Disclaimer: This is a PDF file of an unedited manuscript that has been accepted for publication. As a service to our customers we are providing this early version of the manuscript. The manuscript will undergo copyediting, typesetting, and review of the resulting proof before it is published in its final citable form. Please note that during the production process errors may be discovered which could affect the content, and all legal disclaimers that apply to the journal pertain.

The authors have no conflicting financial interests. 
Transmural inflammation often characterizes $\mathrm{CD}$, whereas in UC the inflammation is typically limited to the mucosa. CD can be associated with intestinal granulomas, strictures, and fistulas, but these are not typical findings in UC [2]. Although it is widely accepted that IBD results from a dysregulated mucosal immune response to environmental factors in genetically susceptible hosts, the precise cause of the disease has not yet been fully elucidated.

\subsection{Genetic susceptibility}

In the last few years, advances in genetic testing have allowed for the completion of many genome-wide association studies (GWAS), which have together identified 163 IBDassociated gene loci, of which 110 are associated with both diseases, 30 are specific for CD, and 23 for UC [3]. These studies indicate that the two major forms of IBD share many common genetic and, therefore, mechanistic features. The genetic variants that confer increased susceptibility to $\mathrm{CD}$ are primarily related to innate immunity, autophagy and phagocytosis [4]. For UC, the genetic variants are mostly related to barrier function. Detailed mapping of chromosome 16 identified polymorphisms within the NOD2 gene (also designated CARDI5 and IBDI) as the most frequently genetic alterations associated with $\mathrm{CD}[5,6]$. This gene encodes a cytoplasmic protein, nucleotide binding oligomerization domain containing 2 (NOD2) that is mainly expressed in monocyte-derived cells $[7,8]$. NOD2 has the essential role of initiating innate immune responses upon intracellular exposure to muramyl-dipeptide (MDP), a breakdown product of peptidoglycan that is present in the cell wall of both Gram-negative and Gram-positive bacteria, leading to the activation of NF- $\mathrm{KB}$ and MAPK signaling pathways [9]. Moreover, NOD2 activation has recently been shown to influence MHC crosspresentation, autophagy induction, and resistance to intracellular bacterial infection [10-12]. The associated risk is dose-dependent, with heterozygous carriers of the NOD2 gene polymorphisms harboring a 2- to 4-fold increased risk of $\mathrm{CD}$, and homozygous or compound heterozygous carriers having a 20- to 40-fold increased risk. Notably, the CD-associated NOD2 gene polymorphisms cause a lossof-function in the NOD2 pathway $[13,14]$. Genetic analyses have shown that polymorphisms in $A T G 16 L 1$ and $I R G M$, two genes that are critically involved in the autophagy pathways, are genetically linked to IBD $[15,16]$. Autophagy is an intracellular process that involves the lysosomal degradation of ingested bacteria, but also self-digestion of organelles.

Interestingly, NOD2 signaling activation is capable of initiating the autophagy process. For effective intracellular digestion and bacterial clearance to be achieved, both intact NOD2 and ATG16L1 functions are required. In contrast, when CD-linked polymorphisms are present in either gene, autophagy in response to MDP is compromised, eventually resulting in reduced bacterial elimination [12]. Thus, these defects may affect adaptive immune responses and predispose to chronic intestinal inflammation.

A critical association between IBD and the IL23R gene has also been described [17]. The $I L 23 R$ gene encodes a subunit of the receptor for interleukin (IL)-23, a pro-inflammatory cytokine also involved in the generation of Th17 cells [18,19]. In addition to IL23R, associations with $\mathrm{CD}$ have been observed in genomic regions encompassing multiple genes involved in the IL-23/Th17 signaling pathway, which is well established in IBD pathogenesis, with the presence of several susceptibility gene loci, such as IL23R, ILI2B, 
$J A K 2$, and STAT3, associated with the development of both UC and CD [5,20]. Variants in $I L 12 B$, which encodes the $\mathrm{p} 40$ subunit of both IL-12 and IL-23, have been associated with IBD as well as other autoimmune disorders, suggesting that a subset of IBD patients share common triggers with these conditions [17]. Significant associations observed in GWAS of UC are within the major histocompatibility complex class II region near HLA-DRA ( $a$ chain). Distinct HLA-DRB1 ( $\beta$-chain) alleles have been associated with both UC and CD $[21,22]$.

\subsection{Environment and microbial factors}

Although genetics variants clearly play a central role in conferring risk for IBD, studies conducted in identical twins clearly demonstrate that the actual development of disease depends on additional factors. A wide range of environmental factors are also thought to confer risk for IBD, including smoking, diet drugs, social stress, and microbial factors [23]. Smoking appears to have a divergent effect on the two forms of IBD, being protective in UC, while increasing disease risk in CD [24]. The implications of diet as a cause of IBD remains equivocal, although data suggest that a "Western" style diet is associated with an increased risk for developing CD, and possibly also UC [25]. Food antigens are thought to be a factor in the pathogenesis of IBD. Non-steroidal anti-inflammatory agents (NSAIDs) have been associated with an increased risk for both $\mathrm{CD}$ and $\mathrm{UC}$, and are thought to influence the progress of IBD by directly damaging the intestinal mucosa through the reduction of prostaglandin production [26]. Social stress has been proposed to also have a role in both diseases. In fact, mood components of perceived stress, such as depression, may play a strong role in mediating the deterioration of IBD [27].

Accumulating evidence suggests that the dynamic balance between commensal flora and host defensive responses within the intestinal mucosa play a pivotal role in both the initiation and perpetuation of IBD [28]. Several studies conducted in patients and animal models have shown the central role of bacteria in the pathogenesis of IBD. For example, the use of antibiotics are effective in subsets of patients with IBD, and most of the mouse models require the presence of intestinal bacteria for inflammation to occur [29]. In addition, several findings suggest that the use of "beneficial bacteria" or probiotics can ameliorate IBD [30,31]. Studies analyzing the composition of the gut microflora have shown that CD patients exhibit a relative lack of Firmicutes and Bacteroidetes and an overrepresentation of Enterobacteria; a reduction in Clostridium spp. and an increase in Escherichia coli (E. Coli) have been reported for UC [32,33]. In addition, there is a marked increase in mucosaassociated $E$. coli in both the ileum and colon, particularly in CD patients, suggesting a possible pathogenic role [34].

Our understanding of the relevant microbial factors affecting the pathogenesis of IBD is still quite incomplete. The use of metagenomic and computational analysis of the microbiome in both patients and animal models of IBD will provide more insight into our understanding of the functional diversity of the flora and, importantly, the regional distribution of disease. 


\subsection{The intestinal epithelium}

The intestinal epithelium represents a physical barrier bacterial entry from the intestinal lumen into the circulation. In order to discriminate between commensal and invasive pathogenic bacteria, intestinal epithelial cells (IECs) exhibit expression of pattern recognition receptors (PRRs), such as toll-like receptors (TLRs), as well as differential regulation of transcription networks in response to their ligands. It is well recognized that under steady state conditions, sensing of microbiota and basal PRRs signaling in IECs is important for intestinal immune homeostasis and constant renewal of the epithelial barrier $[35,36]$. In this context, epithelial-cell-specific NF- $\mathrm{kB}$ activation or suppression seems to be crucial in the suppression and recruitment of immune responses in IBD.

As early as 1972, Shorter et al. proposed the hypothesis that the primary defect in CD may be due to an abnormal gut epithelial barrier, and further stipulated that compromised barrier function allows for increased passage of antigens across the intestinal mucosa, resulting in an overactive immune response and chronic inflammation [37]. Further support for this concept comes from studies demonstrating that patients with IBD display increased intestinal epithelial permeability compared to control subjects and disrupted barrier function that is not isolated to sites of active inflammation. In addition, CD patients have increased gut permeability prior to disease relapse [38]. It remains unclear, however, how barrier dysfunction can lead to chronic intestinal inflammation. In fact, increased permeability alone in healthy individuals is not sufficient to cause IBD. Therefore, there must be some other component in the epithelial-associated dysfunction influencing the development of chronic intestinal inflammation. One hypothesis is that in the presence of epithelial barrier dysfunction, the intestinal epithelial-dendritic cell (DCs) interactions lead to aberrant activation of lamina propria DCs that ultimately results in chronic gut inflammation [39].

Although the intestinal epithelium is not sufficient by itself to sustain the inflammatory process, it plays a primary role in the onset and maintenance of disease. Further investigation in this field of investigation will, therefore, provide more targeted therapies aimed at boosting intestinal epithelial barrier function in order to prevent or treat patients with IBD.

\section{$1.4 \mathrm{Immune}$ responses in IBD}

The combined effects of genetic, environmental, and/or epithelial barrier dysfunction culminate in persistent activation of intestinal mucosal immune responses. Several studies conducted in both patients with IBD and animal models provide substantial characterization of immune-cell populations and inflammatory mediators that lead to the onset and perpetuation of intestinal inflammation. The focus on the adaptive immune response has led to the reasonable consensus that the mucosa of patients with established CD is dominated by $\mathrm{CD} 4^{+}$lymphocytes with a type 1 helper-T-cell (Th1) phenotype. In contrast, the mucosa in patients with UC may be dominated by $\mathrm{CD} 4^{+}$lymphocytes with atypical type 2 helper-Tcell (Th2) phenotype, characterized by the production of TGF- $\beta$ and IL- 5 but not IL- 4 . Another $\mathrm{CD}^{+}{ }^{+} \mathrm{T}$-cell lineage, Th17, has been shown to play an important role in IBD [4042]. Th17 cells are induced by a combination of IL- 6 and TGF- $\beta$, and their expansion is promoted by IL-23 and suppressed by transcription factors required for both Th1 and Th2 
cells [43]. Th17 cells are characterized by the production of large amounts of IL-17A, IL-17F, IL-21 and IL-22. There are two major subsets of Th17 cells: Th17 cells producing IL-17 and Th1/Th17 cells producing both IFN- $\gamma$ and IL-17. The biology IL-17 is still controversial, with some studies showing a pathogenic role, while others suggesting a protective role [44]. However, several studies have shown that IL-17A plays a pathogenic role in IBD, and its inhibition might be beneficial for a subset of patients of IBD with a specific genetic composition.

Compelling evidence in humans and in animal models suggest that $\mathrm{T}$ regulatory cells (Tregs) play an essential role in maintaining intestinal homeostasis. Tregs can arise naturally during thymic development (nTregs) or be induced peripherally from conventional T-cell pools following exposure to low dose antigen (iTreg). In the absence of inflammatory mediators, TGF- $\beta$ promotes the development of Foxp $3^{+}$Treg cells associated with suppression of the inflammatory response [45]. In contrast, in the presence of proinflammatory cytokines such as IL-6, TGF- $\beta$ induces the differentiation of Th17 cells. The complex interactions between pleiotropic factors such as IL-17 and TGF- $\beta$ influence intestinal homeostasis and may affect the onset, perpetuation and relapses in human IBD [45].

Traditionally, the pathogenesis of IBD was primarily attributed to an overly aggressive adaptive immune response against luminal antigens. However, a paradigm shift within the past 10 years led to a novel hypothesis that this chronic, relapsing inflammatory disease of the gut more likely actually results from a primary defect in intestinal innate immunity.

Several studies have provided very important insights into the role of innate cytokine-driven pathways in intestinal mucosal immunity. Interestingly, several innate cytokine may play a dichotomous role, such that any deviation, either positively or negatively, could cause immunologic dysfunction that leads to chronic intestinal inflammation. This is a recurrent concept seen with innate cytokines such as TNF-a, IL-1 $\beta$, IL-18, IL-33 and TL1A, as well as signaling molecules such as NF- $\kappa \mathrm{B}$, MAPK and MyD88 that have long been associated with pro-inflammatory properties [46]. These molecules generate acute inflammatory responses, which result in the elimination of excessive numbers of bacteria for the maintenance of mucosal homeostasis by protecting and/or restoring the integrity of the epithelial barrier. In contrast, during later phase chronic intestinal inflammation, one or more of the homeostatic mechanisms are dysfunctional resulting in either overproduction or underproduction of cytokine secretion. For example, TNF-a was the first pro-inflammatory innate cytokine to be targeted by a clinically applicable neutralizing antibody. However, it has been shown that TNF-a may also exert anti-inflammatory properties depending on the clinical scenario and the cellular target $[30,47]$. Thus, converging evidence suggest that intestinal inflammation develops through distinct stages that differ from each other with regard to immunophenotype and therefore respond to different therapeutic mechanisms.

\section{Animal models of IBD}

Mouse models have been successfully used in the field of IBD to understand the pathogenic mechanisms of human disease. IBD animal models are generated through four major approaches: chemically-induced colitis, adoptive transfer of immune cells, genetically- 
engineering, and spontaneous disease [48] (Table 1). Chemically-induced mouse models are one of the most commonly used approaches because they are simple to generate, and the onset, duration, and severity of inflammation are immediate and controllable. Acute colitis can be induced by an enema containing a contact-sensitizing allergen, trinitrobenzene sulfonic acid (TNBS) in 50\% ethanol solution, intrarectal administration of oxalazone resolved in ethanol, or administration of dextran sulfate sodium (DSS) in drinking water. Several regulatory $T$ cell subsets have been identified using the CD45RB adoptive transfer model [49]. Adoptive transfer of naïve $\mathrm{CD}^{+} \mathrm{T}$ cells $\left(\mathrm{CD} 4^{+} \mathrm{CD} 45 \mathrm{RB}{ }^{\text {high }} \mathrm{T}\right.$ cells) from the spleen of WT mice induces transmural colitis in immune-deficient recipients 6-8 weeks after cell transfer. The colitis of CD45RB model is mediated by Th1 responses associated with IFN- $\gamma$ and TNF-a productions. Conventional genetic knock-out (KO) (i.e. IL-10 ${ }^{-/-}$) or transgenic ( $\mathrm{Tg}$ ) (CD40L tg) models of IBD are genetically-engineered mice that lack or over-express genes of interest; conditional $\mathrm{KO}$ (i.e. CD4/TGF $\beta \mathrm{KO}$ ) or $\mathrm{Tg}$ (i.e. inducible STAT4 $\mathrm{tg}$ ) IBD models are genetically-engineered mice that lack or overexpress the gene of interest in a specific cell type. Knock-in (KI) (i.e. TNF $\Delta \mathrm{ARE}^{+/-}$) IBD models are mice that are-genetically engineered to carry a mutation in the gene of interest [48]. These models are highly useful for dissecting targeted mechanisms of disease, but their relevance is somewhat overshadowed by the fact that their inflammatory phenotype is generated through single mutations, immunological manipulations, or noxious environmental exposures that often are not present in the human condition. Therefore, there remains a great need for spontaneous animal models that resemble the multifactorial nature of the human disease. In this context, the SAMP1Yit/Fc (SAMP) mouse model of CD-like ileitis is particularly suitable for investigating pathogenic mechanisms of experimental CD. These mice develop spontaneous ileitis without genetic, chemical or immunological manipulation. The SAMP immunophenotype has many of the hallmark features of human $\mathrm{CD}$, and importantly, the mice are responsive to therapies that are effective in patients with $\mathrm{CD}$, including the treatment with steroids and anti-TNF-a [50].

\section{Conclusion}

Although no animal model fully recapitulates the clinical and histopathological features of human IBD, each of these classes of mouse models can be used effectively to understand various aspects and mechanisms of IBD pathogenesis. Since many experiments are not feasible using patient specimens obtained from individuals affected by CD and UC, mouse model experimentation should be performed to complement human investigation. Using this approach, it is likely that we will mechanistically improve our understanding of disease pathogenesis and begin to develop new therapeutic strategies, and possibly a cure, for these devastating diseases.

\section{References}

1. Loftus EV Jr, Sandborn WJ. Epidemiology of inflammatory bowel disease. Gastroenterology clinics of North America. 2002; 31:1-20. [PubMed: 12122726]

2. Abraham C, Cho JH. Inflammatory bowel disease. The New England journal of medicine. 2009; 361:2066-2078. [PubMed: 19923578] 
3. Jostins L, Ripke S, Weersma RK, Duerr RH, McGovern DP, Hui KY, et al. Hostmicrobe interactions have shaped the genetic architecture of inflammatory bowel disease. Nature. 2012; 491:119-124. [PubMed: 23128233]

4. Xavier RJ, Podolsky DK. Unravelling the pathogenesis of inflammatory bowel disease. Nature. 2007; 448:427-434. [PubMed: 17653185]

5. Barrett JC, Hansoul S, Nicolae DL, Cho JH, Duerr RH, Rioux JD, et al. Genome-wide association defines more than 30 distinct susceptibility loci for Crohn's disease. Nature genetics. 2008; 40:955962. [PubMed: 18587394]

6. Strober W, Watanabe T. NOD2, an intracellular innate immune sensor involved in host defense and Crohn's disease. Mucosal immunology. 2011; 4:484-495. [PubMed: 21750585]

7. Inohara N, Nunez G. NODs: intracellular proteins involved in inflammation and apoptosis. Nature reviews Immunology. 2003; 3:371-382.

8. Gutierrez O, Pipaon C, Inohara N, Fontalba A, Ogura Y, Prosper F, et al. Induction of Nod2 in myelomonocytic and intestinal epithelial cells via nuclear factor-kappa B activation. The Journal of biological chemistry. 2002; 277:41701-41705. [PubMed: 12194982]

9. Philpott DJ, Sorbara MT, Robertson SJ, Croitoru K, Girardin SE. NOD proteins: regulators of inflammation in health and disease. Nature reviews Immunology. 2014; 14:9-23.

10. Wagner CS, Cresswell P. TLR and nucleotide-binding oligomerization domain-like receptor signals differentially regulate exogenous antigen presentation. Journal of immunology. 2012; 188:686-693.

11. Cooney R, Baker J, Brain O, Danis B, Pichulik T, Allan P, et al. NOD2 stimulation induces autophagy in dendritic cells influencing bacterial handling and antigen presentation. Nature medicine. 2010; 16:90-97.

12. Homer CR, Richmond AL, Rebert NA, Achkar JP, McDonald C. ATG16L1 and NOD2 interact in an autophagy-dependent antibacterial pathway implicated in Crohn's disease pathogenesis. Gastroenterology. 2010; 139:1630-1641. 1641 e1631-1632. [PubMed: 20637199]

13. Bonen DK, Ogura Y, Nicolae DL, Inohara N, Saab L, Tanabe T, et al. Crohn's disease-associated NOD2 variants share a signaling defect in response to lipopolysaccharide and peptidoglycan. Gastroenterology. 2003; 124:140-146. [PubMed: 12512038]

14. Inohara N, Ogura Y, Fontalba A, Gutierrez O, Pons F, Crespo J, et al. Host recognition of bacterial muramyl dipeptide mediated through NOD2. Implications for Crohn's disease. The Journal of biological chemistry. 2003; 278:5509-5512. [PubMed: 12514169]

15. Hampe J, Franke A, Rosenstiel P, Till A, Teuber M, Huse K, et al. A genome-wide association scan of nonsynonymous SNPs identifies a susceptibility variant for Crohn disease in ATG16L1. Nature genetics. 2007; 39:207-211. [PubMed: 17200669]

16. Rioux JD, Xavier RJ, Taylor KD, Silverberg MS, Goyette P, Huett A, et al. Genome-wide association study identifies new susceptibility loci for Crohn disease and implicates autophagy in disease pathogenesis. Nature genetics. 2007; 39:596-604. [PubMed: 17435756]

17. Duerr RH, Taylor KD, Brant SR, Rioux JD, Silverberg MS, Daly MJ, et al. A genome-wide association study identifies IL23R as an inflammatory bowel disease gene. Science. 2006; 314:1461-1463. [PubMed: 17068223]

18. McGeachy MJ, Cua DJ. The link between IL-23 and Th17 cell-mediated immune pathologies. Seminars in immunology. 2007; 19:372-376. [PubMed: 18319054]

19. Hue S, Ahern P, Buonocore S, Kullberg MC, Cua DJ, McKenzie BS, et al. Interleukin-23 drives innate and T cell-mediated intestinal inflammation. The Journal of experimental medicine. 2006; 203:2473-2483. [PubMed: 17030949]

20. Franke A, Balschun T, Karlsen TH, Sventoraityte J, Nikolaus S, Mayr G, et al. Sequence variants in IL10, ARPC2 and multiple other loci contribute to ulcerative colitis susceptibility. Nature genetics. 2008; 40:1319-1323. [PubMed: 18836448]

21. Silverberg MS, Cho JH, Rioux JD, McGovern DP, Wu J, Annese V, et al. Ulcerative colitis-risk loci on chromosomes 1p36 and 12q15 found by genome-wide association study. Nature genetics. 2009; 41:216-220. [PubMed: 19122664]

22. Stokkers PC, Reitsma PH, Tytgat GN, van Deventer SJ. HLA-DR and -DQ phenotypes in inflammatory bowel disease: a meta-analysis. Gut. 1999; 45:395-401. [PubMed: 10446108] 
23. Danese S, Sans M, Fiocchi C. Inflammatory bowel disease: the role of environmental factors. Autoimmunity reviews. 2004; 3:394-400. [PubMed: 15288007]

24. Silverstein MD, Lashner BA, Hanauer SB, Evans AA, Kirsner JB. Cigarette smoking in Crohn's disease. The American journal of gastroenterology. 1989; 84:31-33. [PubMed: 2912028]

25. Amre DK, D'Souza S, Morgan K, Seidman G, Lambrette P, Grimard G, et al. Imbalances in dietary consumption of fatty acids, vegetables, and fruits are associated with risk for Crohn's disease in children. The American journal of gastroenterology. 2007; 102:2016-2025. [PubMed: 17617201]

26. Kaufmann HJ, Taubin HL. Nonsteroidal anti-inflammatory drugs activate quiescent inflammatory bowel disease. Annals of internal medicine. 1987; 107:513-516. [PubMed: 3498419]

27. Helzer JE, Chammas S, Norland CC, Stillings WA, Alpers DH. A study of the association between Crohn's disease and psychiatric illness. Gastroenterology. 1984; 86:324-330. [PubMed: 6690360]

28. Macdonald TT, Monteleone G. Immunity, inflammation, and allergy in the gut. Science. 2005; 307:1920-1925. [PubMed: 15790845]

29. Danis M, Southerland LI, Garrett JM, Smith JL, Hielema F, Pickard CG, et al. A prospective study of advance directives for life-sustaining care. The New England journal of medicine. 1991; 324:882-888. [PubMed: 2000110]

30. Corridoni D, Pastorelli L, Mattioli B, Locovei S, Ishikawa D, Arseneau KO, et al. Probiotic bacteria regulate intestinal epithelial permeability in experimental ileitis by a TNF-dependent mechanism. PloS one. 2012; 7:e42067. [PubMed: 22848704]

31. Gionchetti P, Rizzello F, Helwig U, Venturi A, Lammers KM, Brigidi P, et al. Prophylaxis of pouchitis onset with probiotic therapy: a double-blind, placebo-controlled trial. Gastroenterology. 2003; 124:1202-1209. [PubMed: 12730861]

32. Eckburg PB, Relman DA. The role of microbes in Crohn's disease. Clinical infectious diseases : an official publication of the Infectious Diseases Society of America. 2007; 44:256-262. [PubMed: 17173227]

33. Frank DN, St Amand AL, Feldman RA, Boedeker EC, Harpaz N, Pace NR. Molecularphylogenetic characterization of microbial community imbalances in human inflammatory bowel diseases. Proceedings of the National Academy of Sciences of the United States of America. 2007; 104:13780-13785. [PubMed: 17699621]

34. Barnich N, Darfeuille-Michaud A. Adherent-invasive Escherichia coli and Crohn's disease. Current opinion in gastroenterology. 2007; 23:16-20. [PubMed: 17133079]

35. Fukata M, Arditi M. The role of pattern recognition receptors in intestinal inflammation. Mucosal immunology. 2013; 6:451-463. [PubMed: 23515136]

36. Pastorelli L, De Salvo C, Mercado JR, Vecchi M, Pizarro TT. Central Role of the Gut Epithelial Barrier in the Pathogenesis of Chronic Intestinal Inflammation: Lessons Learned from Animal Models and Human Genetics. Frontiers in immunology. 2013; 4:280. [PubMed: 24062746]

37. Shorter RG, Huizenga KA, Spencer RJ. A working hypothesis for the etiology and pathogenesis of nonspecific inflammatory bowel disease. The American journal of digestive diseases. 1972; 17:1024-1032. [PubMed: 5082428]

38. Gassler N, Rohr C, Schneider A, Kartenbeck J, Bach A, Obermuller N, et al. Inflammatory bowel disease is associated with changes of enterocytic junctions. American journal of physiology Gastrointestinal and liver physiology. 2001; 281:G216-G228. [PubMed: 11408275]

39. Chieppa M, Rescigno M, Huang AY, Germain RN. Dynamic imaging of dendritic cell extension into the small bowel lumen in response to epithelial cell TLR engagement. The Journal of experimental medicine. 2006; 203:2841-2852. [PubMed: 17145958]

40. Fujino S, Andoh A, Bamba S, Ogawa A, Hata K, Araki Y, et al. Increased expression of interleukin 17 in inflammatory bowel disease. Gut. 2003; 52:65-70. [PubMed: 12477762]

41. Kamada N, Hisamatsu T, Okamoto S, Chinen H, Kobayashi T, Sato T, et al. Unique CD14 intestinal macrophages contribute to the pathogenesis of Crohn disease via IL-23/IFN-gamma axis. The Journal of clinical investigation. 2008; 118:2269-2280. [PubMed: 18497880]

42. Fuss IJ, Heller F, Boirivant M, Leon F, Yoshida M, Fichtner-Feigl S, et al. Nonclassical CD1drestricted NK T cells that produce IL-13 characterize an atypical Th2 response in ulcerative colitis. The Journal of clinical investigation. 2004; 113:1490-1497. [PubMed: 15146247] 
43. Yen D, Cheung J, Scheerens H, Poulet F, McClanahan T, McKenzie B, et al. IL-23 is essential for T cell-mediated colitis and promotes inflammation via IL-17 and IL-6. The Journal of clinical investigation. 2006; 116:1310-1316. [PubMed: 16670770]

44. Monteleone I, Sarra M, Pallone F, Monteleone G. Th17-related cytokines in inflammatory bowel diseases: friends or foes? Current molecular medicine. 2012; 12:592-597. [PubMed: 22515978]

45. Bettelli E, Oukka M, Kuchroo VK. T(H)-17 cells in the circle of immunity and autoimmunity. Nature immunology. 2007; 8:345-350. [PubMed: 17375096]

46. Bamias G, Corridoni D, Pizarro TT, Cominelli F. New insights into the dichotomous role of innate cytokines in gut homeostasis and inflammation. Cytokine. 2012; 59:451-459. [PubMed: 22795953]

47. Noti M, Corazza N, Mueller C, Berger B, Brunner T. TNF suppresses acute intestinal inflammation by inducing local glucocorticoid synthesis. The Journal of experimental medicine. 2010; 207:1057-1066. [PubMed: 20439544]

48. Mizoguchi A. Animal models of inflammatory bowel disease. Progress in molecular biology and translational science. 2012; 105:263-320. [PubMed: 22137435]

49. Powrie F, Leach MW, Mauze S, Menon S, Caddle LB, Coffman RL. Inhibition of Th1 responses prevents inflammatory bowel disease in scid mice reconstituted with CD45RBhi CD4+ T cells. Immunity. 1994; 1:553-562. [PubMed: 7600284]

50. Pizarro TT, Pastorelli L, Bamias G, Garg RR, Reuter BK, Mercado JR, et al. SAMP1/YitFc mouse strain: a spontaneous model of Crohn's disease-like ileitis. Inflammatory bowel diseases. 2011; 17:2566-2584. [PubMed: 21557393] 


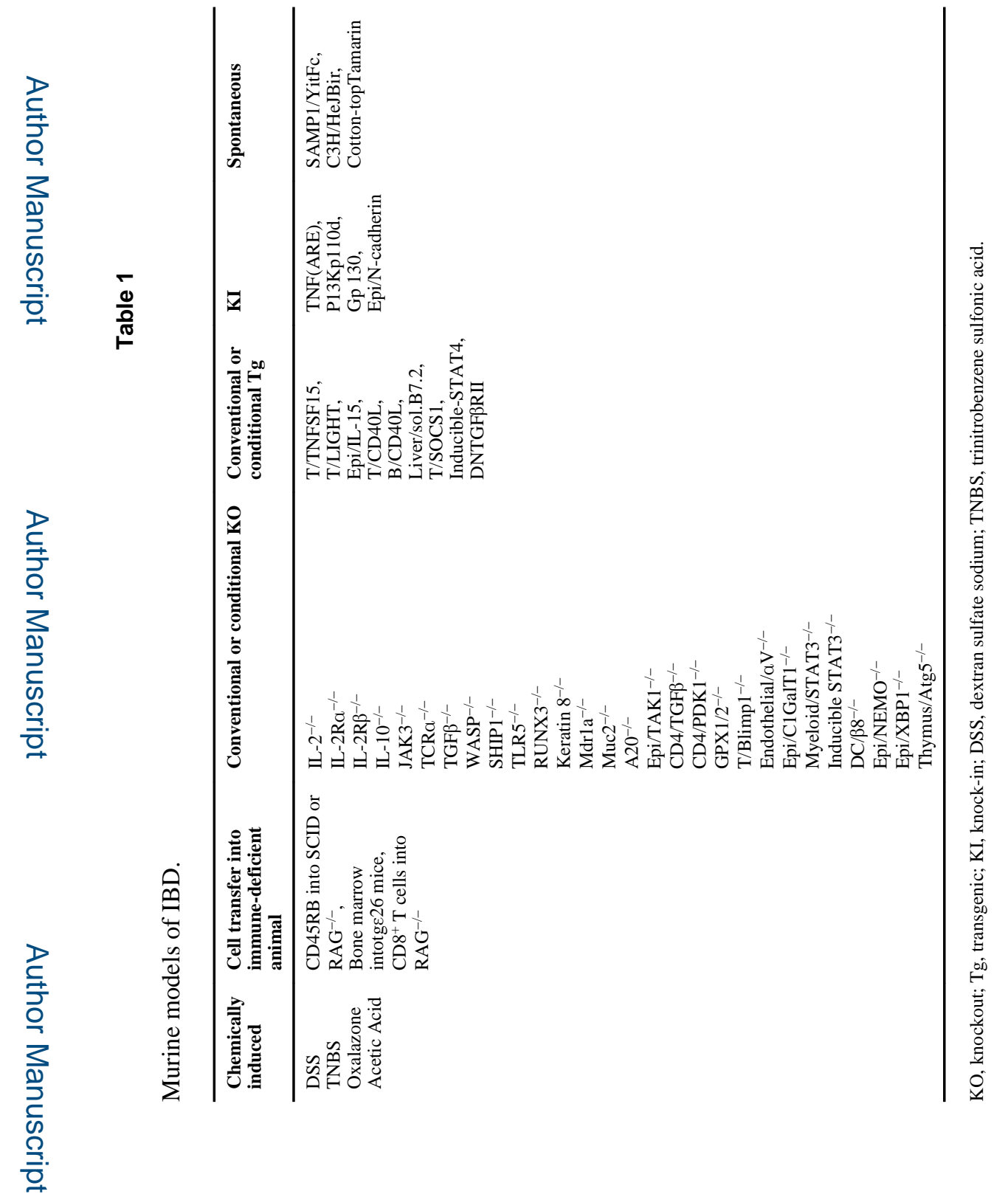

